\title{
Microsatellite instability and ploidy status define three categories with distinctive prognostic impact in endometrioid endometrial cancer
}

\author{
Cristina Bilbao-Sieyro ${ }^{1,2}$, Raquel Ramírez-Moreno ${ }^{1,2}$, Germán Rodríguez- \\ González 1,2, Orlando Falcón ${ }^{1,3}$, Laureano León ${ }^{1,4}$, Santiago Torres $^{2}$, Leandro \\ Fernández $^{1,5}$, Sergio Alonso ${ }^{6}$, Nicolás Díaz-Chico ${ }^{1,2}$, Manuel Perucho6,7,8 and Juan \\ Carlos Díaz-Chico ${ }^{1,2}$ \\ ${ }^{1}$ Cancer Research Institute of The Canary Islands (ICIC), Las Palmas de Gran Canaria, Canary Islands, Spain \\ 2 Biochemistry, Molecular Biology and Physiology Department, Molecular and Translational Endocrinology Group, Institute \\ for Biomedical and Health Research, Faculty of Health Sciences, Universidad de Las Palmas de Gran Canaria, Las Palmas de \\ Gran Canaria, Canary Islands, Spain \\ 3 Obstetrics and Gynecology Department, Hospital Universitario Materno-Insular de Canarias, Las Palmas de Gran Canaria, \\ Canary Islands, Spain \\ ${ }^{4}$ Pathology Department, Hospital Universitario Materno-Insular de Canarias, Las Palmas de Gran Canaria, Canary Islands, \\ Spain \\ ${ }^{5}$ Clinical Sciences Department, Molecular and Translational Endocrinology Group, Institute for Biomedical and Health \\ Research, Universidad de Las Palmas de Gran Canaria, Las Palmas de Gran Canaria, Canary Islands, Spain \\ ${ }^{6}$ Institute of Predictive and Personalized Medicine of Cancer (IMPPC), Barcelona, Spain \\ 7 Sanford-Burnham Medical Research Institute (SBMRI), La Jolla, CA, USA \\ ${ }^{8}$ Instituciò Catalana de Recerca i Estudis Avançats (ICREA), Passeig Lluis Companys 23, Barcelona, Spain \\ Correspondence to: Manuel Perucho, email: mperucho@sanfordburnham.org
}

Keywords: endometroid, endometrial cancer, microsatellite instability, aneuploidy, survival

Received: June 19, $2014 \quad$ Accepted: July 06, $2014 \quad$ Published: July 08, 2014

This is an open-access article distributed under the terms of the Creative Commons Attribution License, which permits unrestricted use, distribution, and reproduction in any medium, provided the original author and source are credited.

\section{ABSTRACT}

Microsatellite instability (MSI) and aneuploidy are inversely related phenomena. We tested whether ploidy status influences the clinical impact of MSI in endometrioid endometrial cancer (EEC). We analyzed 167 EECs for MSI and ploidy. Tumors were classified in three categories according to MSI and ploidy status. Associations with clinicopathological and molecular variables, survival, and treatment response were assessed.

All MSI tumors (23\%) were scored as diploid, and $14 \%$ of microsatellite stable (MSS) tumors presented aneuploidy. MSI tumors associated with older age at diagnosis, non-obesity, high histological grade, and advanced surgical stage. MSS-aneuploid tumors also associated with higher grade and advanced stage. In multivariate survival analysis MSI did not influence disease-free survival (DFS) or cancer-specific survival (CSS). However, when just diploid tumors were considered for the analysis, MSI significantly contributed to worse DFS and CSS, and the same was observed for aneuploidy when MSS tumors were analyzed alone. In diploid tumors, a differential response to postoperative radiotherapy (RT) was observed according to MSI, since it predicted poor DFS and CSS in the multivariate analysis.

We conclude that ploidy status influences the clinical impact of MSI in EEC. Among diploid tumors those with MSI have poor clinical outcome and respond worse to RT. 


\section{INTRODUCTION}

Endometrial cancer (EC) is the most common pelvic gynecological malignancy and the fourth leading cause of female cancer in occidental countries [1]. Although the majority of cases follows an indolent course and are cured by surgery alone, about $20 \%$ of patients recur and die by disease despite receiving adjuvant therapies [1]. Two mayor types of EC are distinguished based on epidemiology, histopathology and clinical behavior. Type I endometrioid EC, which is the most abundant (about $80 \%$ ), arises in relatively younger women with a history of unopposed estrogenic stimulation, usually has differentiated or moderately differentiated histological grade with non-aggressive behavior. Type II non endometrioid EC (mostly papillary serous and clear cell), commonly occurs in older women with a background unrelated to unopposed estrogen exposure, usually is high grade and has worse prognosis [2,3]. The endometrioid type frequently presents microsatellite instability (MSI), estrogen (ER) and progesterone (PR) receptors expression, PTEN, $K$-ras and $\beta$-Catenin mutations, epigenetic silencing of $A P C$ and a near diploid DNA content, although aneuploidy has also been detected in around $20 \%$ of this type [4]. In contrast, the non endometrioid type is mostly aneuploid, with lack or weak ER and PR expression, $p 53$ mutations and HER2 overexpression [2, $3]$.

MSI is present in the majority of tumors of the hereditary nonpolyposis colorectal cancer (HNPCC) syndrome, and also in a subset (15-20\%) of sporadic tumors [5-8], that accumulate hundreds of thousands of somatic clonal mutations in simple repeat sequences (microsatellites) as a result of a defective mismatch repair (MMR) system [6, 9]. In colorectal cancer (CRC) MSI tumors exhibit pseudodiploidy and better outcome compared to tumors without MSI (MSS), which frequently are aneuploid $[6,9,10]$. In CRC, loss of expression of DNA double strand breaks repair proteins has been associated to increased aneuploidy and poorer survival [11-14]. Accordingly, three different pathways based on the combination of these two anomalies, namely, MSIdiploid, MSS-diploid and MSS-aneuploid, have been proposed to better stratify CRC according to clinical characteristics and outcome [15-17].

In EC MSI is mainly present in near-diploid tumors of endometrioid histology [3], and shows different gene mutation profile compared to gastrointestinal tumors of the mutator phenotype [18-20], associating with $K$-ras and PTEN mutations [3]. Published data about the clinical impact of MSI are conflicting [21-26], and recent studies have related aneuploidy to worse clinical behavior $[4,27$, 28].

In this study, we tested whether MSI and aneuploidy could interfere when determining its influence on clinicopathological characteristics and outcome in endometrioid EC based on the inverse relationship found between MSI and aneuploidy, and the precedents about the clinical effect of the combination of these two genomic instability phenotypes in CRC.

\section{RESULTS}

In our series of 167 patients with endometrioid EC, all tumors with MSI presented $M L H 1$ promoter methylation and had a DNA-quasy-diploid content, and all aneuploid tumors were MSS. A single patient with presence of MSI and aneuploidy in the same tumor sample was excluded to simplify categories. Accordingly, tumors were divided in three categories: MSI, MSSdiploid and MSS-aneuploid. MSI and aneuploidy were detected in $33(20 \%)$ and 24 (14\%) cases respectively. The distribution of the subtypes according to demographic, surgicopathological and molecular variables of patients is shown in Table 1.

MSI tumors exhibited distinctive demographic features compared to MSS-aneuploid and MSS-diploid both of which shared similar features. Compared to MSS patients, those with MSI were older, relatively slim and had fewer births, in the multivariate analysis. Regarding clinico-pathological features, MSI and MSSaneuploid tumors behaved similarly and exhibited marked differences compared to the MSS-diploid category. Thus, MSI and MSS-aneuploid tumors associated with advanced stage of progression $(\mathrm{p}=0.001)$ undifferentiated histological grade $(\mathrm{p}=0.005)$, and invasion of vascular space $(\mathrm{p}<0.001)$. With respect to molecular parameters, MSI tumors had higher frequency of $K$-ras $(\mathrm{p}<0.001)$ and $P T E N(\mathrm{p}=0.01)$ mutations, and $A P C$ promoter methylation $(\mathrm{p}<0.001)$. MSI and MSS-aneuploid categories associated with high S-phase $(\mathrm{p}<0.001)$.

Univariate survival analysis (summary in Supplementary information, Tables S1 and S2) of the whole series showed that MSI, aneuploidy, older age at diagnosis, advanced stage, higher grade, myometrial invasion, vascular invasion, and radiation therapy, among others, were associated with worse DFS and CSS. Survival curves of the whole series stratified according to the three defined categories showed significant better DFS and CSS for MSS-diploid tumors (Fig. 1). The potential of MSI and aneuploidy as prognostic markers was estimated by multivariate analyses in the whole series and in the diploid and MSS groups (Tables 2 and 3). In the whole series, the basic multivariate DFS and CSS models included age at diagnosis, surgical stage and histological grade. After a stepwise procedure, MSI did not show significant prognostic value for DFS or CSS, and aneuploidy did for CSS ( $\mathrm{p}=0.01)$.

In the DNA-diploid group, age, grade and stage were also present in the basic DFS and CSS models. When MSI was tested, it significantly associated with poor DFS $(\mathrm{p}=0.02)$ and CSS $(\mathrm{p}=0.02)$. In the MSS group, 
Table 1: MSI and ploidy status \& demographic, surgico-pathological, and molecular characteristics of endometrioid endometrial cancer (EEC)

\begin{tabular}{|c|c|c|c|c|c|c|}
\hline Characteristic & $\mathrm{n}$ & $\begin{array}{l}\text { MSI-diploid } \\
\qquad(\mathrm{n}=33)^{2}\end{array}$ & $\begin{array}{l}\text { MSS-diploid } \\
\qquad(\mathrm{n}=110)^{\mathrm{a}}\end{array}$ & $\begin{array}{l}\text { MSS-aneuploid } \\
\qquad(\mathrm{n}=24)^{2}\end{array}$ & p-value & $\begin{array}{l}\text { MSI vs } \\
\text { MSS } \\
\text { p-value* }\end{array}$ \\
\hline Age at diagnosis (years) ${ }^{1}$ & 167 & $67.3 \pm 9.9$ & $62.5 \pm 9.4$ & $62.2 \pm 11.8$ & 0.040 & 0.035 \\
\hline \multicolumn{7}{|l|}{ BMI $\left(\mathrm{kg} / \mathrm{m}^{2}\right)$} \\
\hline$<30$ & 66 & $21(32)(64)^{b}$ & $37(56)(34)^{b}$ & $8(12)(33)^{b}$ & \multirow{2}{*}{0.007} & \multirow{2}{*}{0.032} \\
\hline$>30$ & 101 & $12(12)(36)$ & $73(72)(66)$ & $16(16)(67)$ & & \\
\hline \multicolumn{7}{|l|}{ Diabetes } \\
\hline no & 125 & $22(18)$ & $84(67)$ & $19(15)$ & \multirow{2}{*}{$>0.1$} & \\
\hline yes & 42 & $11(26)$ & $26(62)$ & $5(12)$ & & \\
\hline \multicolumn{7}{|l|}{ Hypertension } \\
\hline no & 84 & $17(20)$ & $53(63)$ & $14(17)$ & \multirow{2}{*}{$>0.1$} & \\
\hline yes & 83 & $16(19)$ & $57(69)$ & $10(12)$ & & \\
\hline Age of menarche (years) ${ }^{2}$ & 167 & $13(11-19)$ & $13(9-18)$ & $13(10-17)$ & $>0.1$ & \\
\hline \multicolumn{7}{|l|}{ No. of births } \\
\hline $0-1$ & 45 & $15(33)(45)^{\mathrm{b}}$ & $25(56)(23)^{b}$ & $5(11)(21)^{b}$ & \multirow{3}{*}{0.016} & \multirow{3}{*}{0.023} \\
\hline $2-3$ & 52 & $9(17)(27)$ & $34(65)(31)$ & $9(17)(38)$ & & \\
\hline$>3$ & 70 & $9(13)(27)$ & $51(73)(46)$ & $10(14)(42)$ & & \\
\hline Total pregnancy months ${ }^{2,3}$ & 167 & $18(0-81)$ & $27(0-126)$ & $27(0-90)$ & 0.085 & ns \\
\hline \multicolumn{7}{|l|}{ Menopause } \\
\hline no & 17 & $2(17)$ & $10(59)$ & $5(33)$ & \multirow{2}{*}{$>0.1$} & \\
\hline yes & 150 & $31(24)$ & $100(67)$ & $19(16)$ & & \\
\hline Age of menopause (years) ${ }^{2}$ & 150 & $52(40-57)$ & $51(30-60)$ & $48(44-55)$ & 0.043 & ns \\
\hline Years of menstruation ${ }^{1,4}$ & 167 & $34.6 \pm 5.5$ & $32.2 \pm 6.2$ & $31.6 \pm 4.9$ & 0.087 & ns \\
\hline Years from menopause to diagnosis' & 167 & $16.6 \pm 10.7$ & $13.1 \pm 8.9$ & $14.1 \pm 11.1$ & $>0.1$ & \\
\hline \multicolumn{7}{|l|}{ Stage } \\
\hline I & 115 & $16(14)(16)^{e}$ & $86(75)$ & $13(11)(13)^{d}$ & \multirow{3}{*}{0.001} & \\
\hline II & 27 & $8(30)(30)$ & $16(59)$ & $3(11)(16)$ & & \\
\hline III & 25 & $9(36)(53)$ & $8(32)$ & $8(32)(50)$ & & \\
\hline \multicolumn{7}{|l|}{ Grade } \\
\hline '1 & 88 & $14(16)(17)^{c}$ & $68(77)$ & $6(7)(8)^{d}$ & \multirow{3}{*}{0.005} & \\
\hline 2 & 51 & $10(20)(25)$ & $30(59)$ & $11(22)(27)$ & & \\
\hline 3 & 28 & $9(32)(43)$ & $12(43)$ & $7(25)(37)$ & & \\
\hline \multicolumn{7}{|l|}{ Myometrial infiltration } \\
\hline $0-<50 \%$ & 121 & $25(21)$ & $81(67)$ & $15(12)$ & \multirow{2}{*}{$\mathrm{ns}$} & \\
\hline$>50 \%$ & 46 & $8(17)$ & $29(63)$ & $9(20)$ & & \\
\hline \multicolumn{7}{|l|}{ Vascular invasion } \\
\hline no & 122 & $18(15)(16)^{e}$ & $92(75)$ & $12(10)(12)^{d}$ & \multirow{2}{*}{0.000} & \\
\hline yes & 45 & $15(33)(45)$ & $18(40)$ & $12(27)(40)$ & & \\
\hline \multicolumn{7}{|l|}{ Treatment } \\
\hline surgery & 77 & $14(18)$ & $54(70)$ & $9(12)$ & & \\
\hline surgery+radiotherapy & 90 & $19(21)$ & $56(62)$ & $15(17)$ & ns & \\
\hline $\mathrm{ER}$ (fmol/mg prot.) $)^{2}$ & 167 & $58(0-280)$ & $95(0-737)$ & $48(0-376)$ & 0.032 & \\
\hline $\mathrm{PgR}$ (fmol/mg prot.) $)^{2}$ & 167 & $223(0-1684)$ & $330(0-2069)$ & $157(0-1724)$ & ns & \\
\hline S-phase (percentaje) $)^{2}$ & 167 & $7.7(0.4-24.0)$ & $4.3(0.7-21.4)$ & $7.0(1.2-24.7)$ & 0.000 & \\
\hline K-ras & & & & & & \\
\hline wild-type & 143 & $20(14)$ & $102(71)$ & $21(15)$ & & \\
\hline mutant & 24 & $13(54)$ & $8(33)$ & $3(13)$ & 0.000 & \\
\hline PTEN & & & & & & \\
\hline wild-type & 108 & $15(14)$ & $73(68)$ & $20(19)$ & & \\
\hline mutant & 59 & $18(31)$ & $37(63)$ & $4(7)$ & 0.010 & \\
\hline
\end{tabular}




\begin{tabular}{|c|c|c|c|c|c|}
\hline B-catenin & & & & & \\
\hline wild-type & 133 & $28(21)$ & $86(65)$ & $19(14)$ & \\
\hline mutant & 34 & $5(15)$ & $24(71)$ & $5(15)$ & IIS \\
\hline APC & & & & & \\
\hline unmethylated & 109 & $10(9)$ & $84(77)$ & $15(14)$ & 0,000 \\
\hline methylated & 55 & $23(42)$ & $24(44)$ & $8(15)$ & 0.000 \\
\hline
\end{tabular}

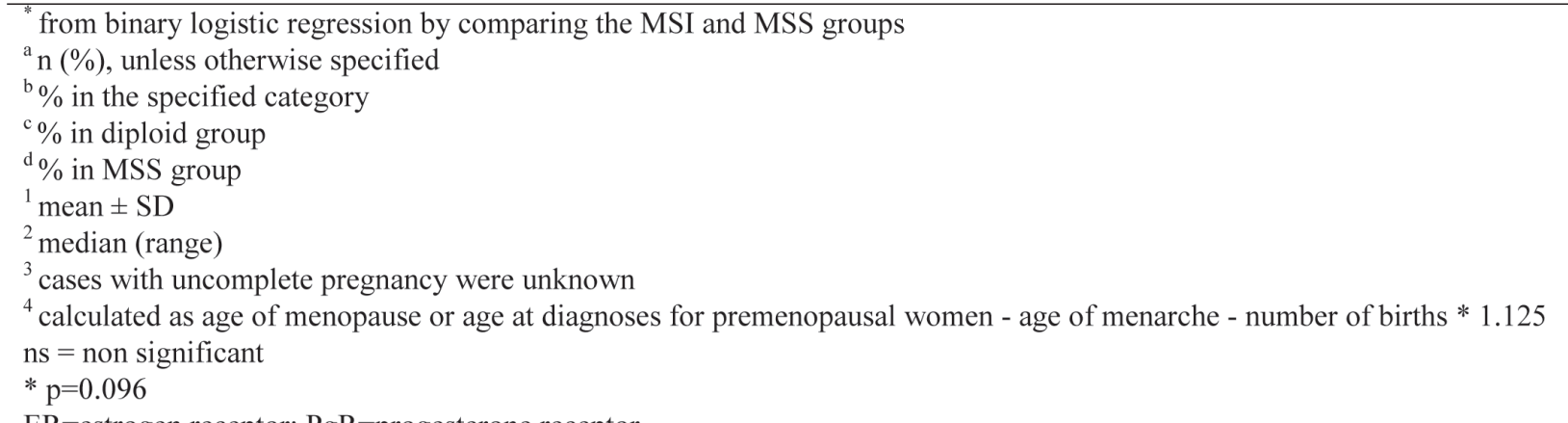

$\mathrm{ER}=$ estrogen receptor; $\mathrm{PgR}=$ progesterone receptor p-values below 0.05 are in bold type

Table 2: Multivariate disease-free survival analysis of EEC according to MSI and ploidy

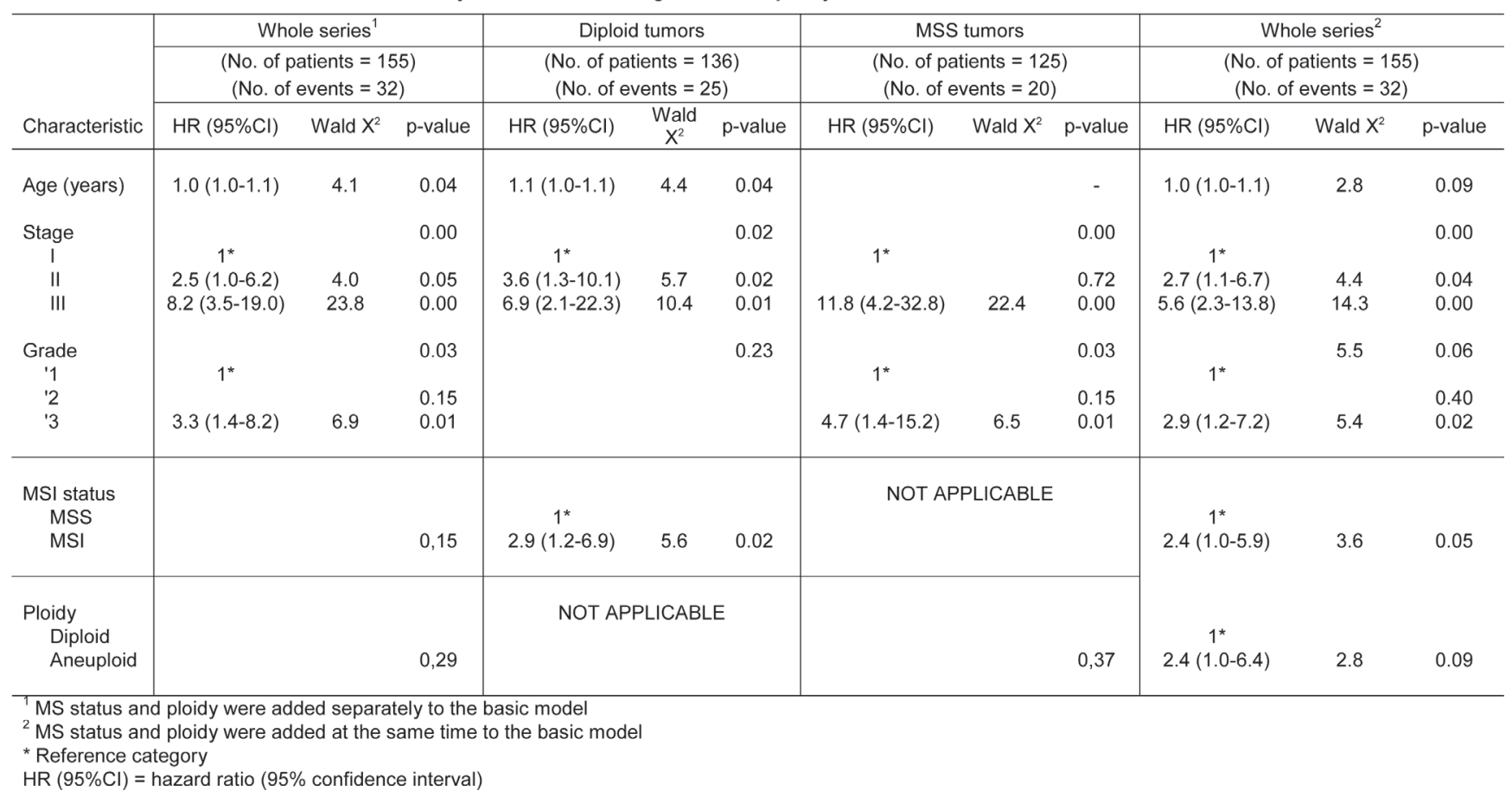

stage and grade for DFS, and age, stage and grade for CSS, were included in the basic model. Aneuploidy was not associated with DFS, but remained significant for CSS $(\mathrm{p}=0.02)$.

The significant prognostic value of MSI in the DNA-diploid group, and of aneuploidy in the MSS group, prompted us to estimate the impact of adding both variables simultaneously to the basic model in the whole series. As a result, MSI was significantly associated with poor DFS ( $\mathrm{p}=0.05$ ), and MSI and aneuploidy with worse CSS ( $<<0.05$ and $p<0.01$, respectively). Thus, patients with MSI had an increased risk of recurrence and die by disease 2.4 (95\% CI, 1.0 to 5.9$)$ and 2.5 times $(95 \% \mathrm{CI}$, 1.0-6.2) respectively, compared to MSS-diploid tumors.

The clinical impact of MSI was also assessed among the subgroup of patients treated with postoperative radiotherapy (RT) (Figure 2, univariate analyses are summarized in Supplementary information, Table S3). In the whole series of these treated patients, age, stage and grade, and in the DNA-diploid group, age and stage, were incorporated in the basic model for DFS and CSS. According to the multivariate analysis, MSI lacked independent value for DFS and CSS in the whole series. However, in the group of diploid tumors, MSI predicted 
Table 3. Multivariate cancer-specific survival analysis of EEC according to MSI and ploidy

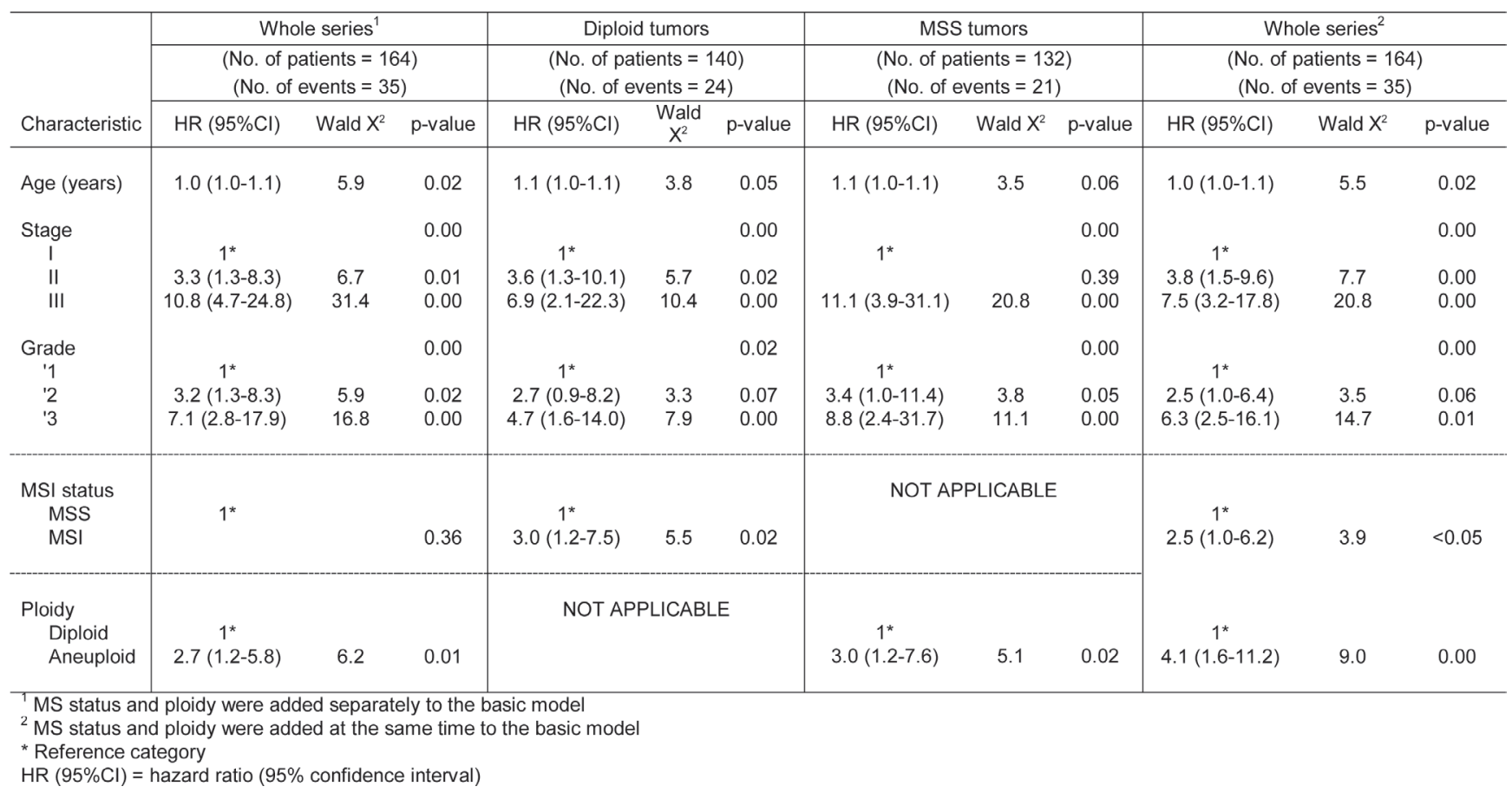

a)

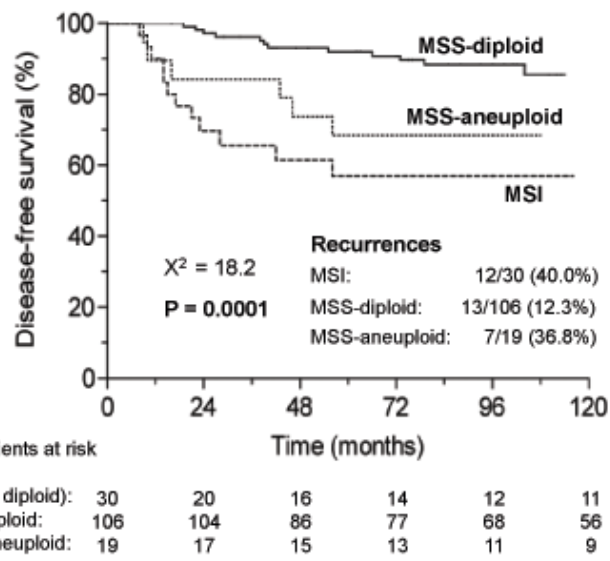

b)

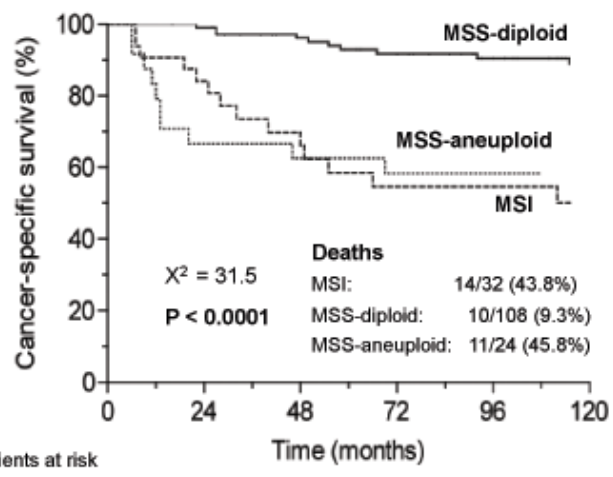

No. Patients at risk

$\begin{array}{ccccc}26 & 19 & 15 & 13 & 11 \\ 107 & 92 & 79 & 70 & 59 \\ 17 & 16 & 15 & 12 & 10\end{array}$

Figure 1: Kaplan-Meier curves for a) disease free survival and b) cancer-specific survival of the three categories of tumors defined by microsatellite instability and ploidy status in the whole series. Number of patients at risk, i.e. disease-free (a) or surviving (b), at time-points $0,24,48,72,96$ and 120 months, are shown below the x-axis of each graph. 
Table 4. Multivariate survival analysis for MSI after treatment with radiotherapy

\begin{tabular}{|c|c|c|c|c|c|c|c|c|c|c|c|c|}
\hline \multirow[b]{4}{*}{ Characteristic } & \multicolumn{6}{|c|}{ Disease-free survival } & \multicolumn{6}{|c|}{ Cancer-specific survival } \\
\hline & \multicolumn{3}{|c|}{ Whole series } & \multicolumn{3}{|c|}{ Diploid tumors } & \multicolumn{3}{|c|}{ Whole series } & \multicolumn{3}{|c|}{ Diploid tumors } \\
\hline & \multicolumn{3}{|c|}{$\begin{array}{c}(\text { No. of patients }=85) \\
(\text { No. of events }=25)\end{array}$} & \multicolumn{3}{|c|}{$\begin{array}{c}(\text { No. of patients }=73) \\
(\text { No. of events }=19)\end{array}$} & \multicolumn{3}{|c|}{$\begin{array}{c}\text { (No. of patients }=89) \\
(\text { No. of events }=25)\end{array}$} & \multicolumn{3}{|c|}{$\begin{array}{c}(\text { No. of patients }=74) \\
(\text { No. of events }=17)\end{array}$} \\
\hline & $\mathrm{HR}(95 \% \mathrm{Cl})$ & $\begin{array}{c}\text { Wald } \\
X^{2}\end{array}$ & p-value & $\mathrm{HR}(95 \% \mathrm{Cl})$ & $\begin{array}{c}\text { Wald } \\
X^{2}\end{array}$ & $p$-value & $\mathrm{HR}(95 \% \mathrm{Cl})$ & $\begin{array}{c}\text { Wald } \\
X^{2}\end{array}$ & $p$-value & $\mathrm{HR}(95 \% \mathrm{Cl})$ & $\begin{array}{c}\text { Wald } \\
X^{2}\end{array}$ & $\mathrm{p}$-value \\
\hline Age (years) & $1.0(1.0-1.1)$ & 3.0 & 0.08 & $1.1(1.0-1.1)$ & 3.7 & 0.06 & $1.1(1.0-1.1)$ & 6.0 & 0.01 & $1.1(1.0-1.1)$ & 4.6 & 0.03 \\
\hline Stage & & & 0.03 & & & 0.30 & & & 0.00 & & & 0.07 \\
\hline 1 & $1^{*}$ & & & & & & $1^{*}$ & & & $1^{*}$ & & \\
\hline II & & & 0.17 & & & & $2.6(0.9-7.8)$ & 3.0 & 0.08 & $4.1(1.1-14.9)$ & 4.7 & 0.03 \\
\hline III & $4.5(1.5-13.3)$ & 7.1 & 0.01 & & & & $7.5(2.5-22.9)$ & 12.5 & 0.00 & $4.1(0.9-20.0)$ & 3.2 & 0.07 \\
\hline Grade & & & 0.16 & & & - & & & 0.06 & & & - \\
\hline '1 & & & & & & & $1^{*}$ & & & & & \\
\hline '2 & & & & & & & & & 0.21 & & & \\
\hline '3 & & & & & & & $3.9(1.3-11.7)$ & 5.7 & 0.02 & & & \\
\hline \multicolumn{13}{|l|}{ MS status } \\
\hline MSS & & & & $1^{*}$ & & & & & & $1^{*}$ & & \\
\hline $\mathrm{MSI}$ & & & 0,23 & $3.6(1.2-10.7)$ & 5.4 & 0.02 & & & 0.73 & $3.4(1.1-11.1)$ & 4.2 & 0.04 \\
\hline
\end{tabular}

* Reference category

$\mathrm{HR}(95 \% \mathrm{Cl})=$ hazard ratio $(95 \%$ confidence interval $)$
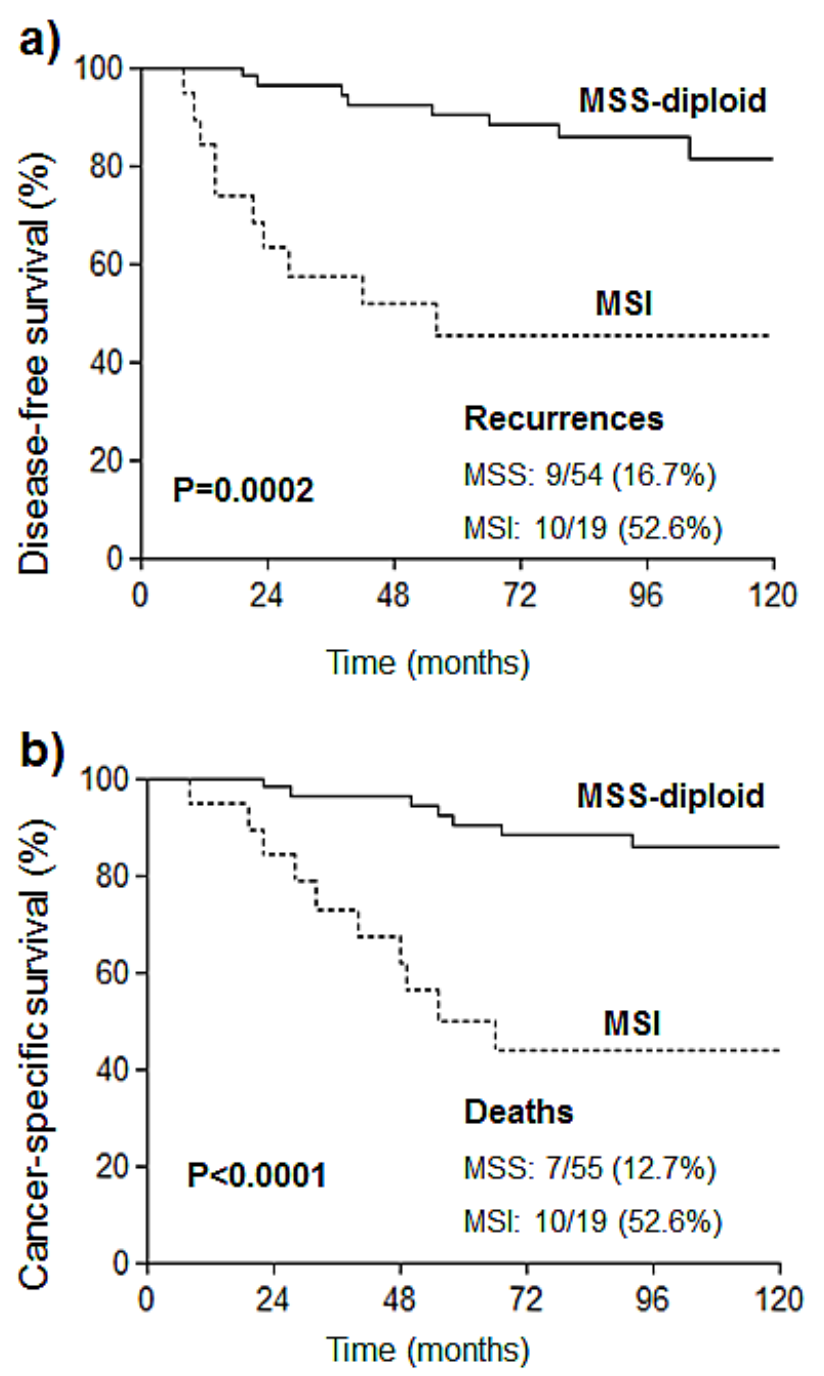

Figure 2: Kaplan-Meier curves for a) disease free survival and b) cancer-specific survival of EC patients with diploid tumors (MSS or MSI) who were treated with radiotherapy. 
worse DFS $(\mathrm{p}=0.02)$ and CSS $(\mathrm{p}=0.04)$ (Table 4).

\section{DISCUSSION}

In EC MSI and aneuploidy appear as mutually exclusive genomic alterations with clinical implications, although clinical data regarding MMR deficiency remain conflicting. In this work we hypothesized whether the clinical relevance of MSI in endometrioid EC could be clarified by studying this genetic alteration under the perspective of three alternative genomic cancer pathways, namely, MSI, MSS-diploid, and MSS-aneuploid. The clear known differences between endometrioid and nonendometrioid tumors $[2,3]$ justify the exclusion of nonendometrioid tumors from our study, since they can act as a confounding factor [26]. Another circumstance that added homogeneity to the stratification of our series is that all MSI tumors were diploid and had $M L H 1$ promoter methylation. This refers to a non-hereditary origin [29], especially relevant when studying the relationship between MSI and, at least, some demographic variables.

Patient age, obesity and nulliparity are three known EC risk factors. Although previous studies failed to find any relation between MSI and age [22, 24], it has been shown that women displaying MSI and methylated $M L H 1$ are significantly older $[30,26]$. This agrees with our observations and with the fact that $M L H 1$ methylation is known to be an age related phenomena [31-33]. The inverse relationship between MSI and BMI is in accordance to other reports [30]. In CRC the association between MSI and nulliparity has also been published [32]. Although a connection between estrogen exposure and reduced risk of acquiring MMR deficiency has been suggested $[32,34]$, further studies are required to elucidate the molecular bases.

In the whole series, MSI cases associated with higher FIGO grade, advanced surgical stage and lymphovascular invasion compared to MSS-diploid tumors. For each clinical feature, several groups have reported similar results, either in EC, without distinction of histological types, or in the endometrioid subtype [24, 26], although discordant findings have also been published $[22,24,30,26]$. In CRC, the association between MSI and poor differentiated grade is well established [10]. Our data show that MSI might manifest in clones with undifferentiated aggressive appearing histology among tumors with a background of DNA-diploid content. MSS-aneuploid subtype tumors had pathological features similar to those of MSI tumors, since they frequently presented higher grade, advanced stage and vascular involvement. The association of aneuploidy with a more aggressive clinical phenotype in EC is well documented $[4,27,28]$. According to our data, MSS-diploid tumors display a more benign phenotype (differentiated grade, early stage and absence of vascular invasion) compared to MSI and MSS-aneuploid tumors.
We found that MSI tumors were more likely to present lower ER levels and a trend towards lower PgR, which contrast with the fact that endometrioid tumors are prototypically associated with estrogen stimulation and generally express both receptors [2]. The reason for this observation could be the high prevalence of MSI in poor differentiated grades, since most high grade EC show weak ER and PgR expression [2]. In CRC, either arising in Lynch syndrome families or not, significantly lower hormone receptor levels have been described in MSI tumors [35, 36].

Our EC MSI tumors also showed increased S-phase compared to MSS-diploid tumors. In this line, cyclin A, which is necessary for DNA replication and S-phase entry, has also been related to the MSI phenotype and to cell proliferation in EC [37, 38].

As previously reported [39, 40, 3], our results show that MSI was positively related to K-ras and PTEN mutations and $A P C$ promoter hypermethylation, whereas inversely associated with $\beta$-catenin mutations. It is well known that in CRC the association of MSI with these molecular variables is quite different. For example, $K$-ras mutations mainly coexist with MSS tumors, while $\beta$-catenin mutations and $A P C$ promoter methylation are characteristic of MSI tumors $[6,41,42]$.

The absence of a significant impact of MSI on survival was recently reported by Zighelboim et al [26] and by others previously in endometrioid EC, and by Basil et al [21] and McDonnald et al [22], among others, in EC (endometrioid and non-endometrioid). Conversely, several groups have referred an association of MSI with better $[23,24]$, or worse [25] outcome in series including only endometrioid tumors or both histological types. As for the prognostic value of ploidy in EC, latest publications suggest that is a statistically independent prognosticator of poor outcome through multivariate analysis $[4,27,28]$.

Our most relevant finding in the multivariate survival analysis was that both MSI and aneuploidy remained as significant prognosticators of worse DFS and CSS when aneuploidy and MSI where, respectively, excluded from the corresponding survival analyses. In the whole series, the simultaneous inclusion of both variables influenced their respective outcome values, making (marginally) significant its relationship with DFS, and significant its contribution to CSS. This suggests that when analysing the prognostic value of MSI or aneuploidy, each variable could act as a confounding factor for the other. It is noteworthy that the number of recurrences $(40 \%)$ and death $(44 \%)$ of patients with MSI EC tumors in our series was higher than previously reported by some studies [22-24, 26]. In CRC, the interference between these variables in clinical outcome has also been proposed, and cumulative evidence associates MSI-diploidy with good prognosis $[16,17]$. The strong local and systemic antitumoral immune response observed in MSI CRC have been proposed as a possible mechanism to explain 
the increased survival rates in patients with MSI tumors [43]. However, in endometrioid EC, Risinger et al [44] reported that significant differences in tumor infiltrating lymphocytes derived transcripts, do not occur between tumors with and without MSI. Therefore, a relevant task for future research will be to elucidate the mechanism beneath the different immune response of CRC and EC with MSI, and why the influence of MSI-diploidy on patient's survival in EC is just the opposite of that observed in CRC.

Finally, we have also observed that among diploid tumors, MSI predicts worse DFS and CSS in patients treated with postoperative RT. We have previously suggested the predictive role of MSI in early staged radiation-treated endometrioid EC [45]. There are few related studies, mostly in preoperative RT rectal treated tumors, and with discordant results [46-48]. As previously pointed, the worse response of MSI tumors to RT could be related to the suggested increased malignant potential of $M L H 1$ null mice after ionizing radiation exposure due to the activation of mitotic recombinational events [49].

Due to the combination of low incidence of MSI and aneuploidy and of recurrences and cancer-specific deaths inherent to this non-aggressive endometrial cancer type, the present work has limited statistical power. Nevertheless, there was sufficient data (at least 5 events for each explanatory variable) to get reproducible results from multivariate regression analysis. Future work thus seems warranted, as it may assist to a better stratification of patients for election of modality of treatment. In summary, our data show that the three groups described here based on MSI status and ploidy might represent different molecular pathways of tumorigenesis and progression of endometrioid endometrial cancer with different prognostic and predictive significance.

\section{MATERIALS AND METHODS}

\section{Study Participants and Clinical Data}

A series of 167 patients with endometrioid EC (surgical stage I-III), was selected from a previously described Caucasian population-based series of 204 patients with EC, diagnosed and treated between 1990 and 1999 [40]. Exclusion causes from the original EC series were: non endometrioid histology, fulfill the Amsterdam criteria of HNPCC and lack of fresh tumor sample to perform flow cytometry. A single patient with presence of MSI and aneuploidy in the same tumor sample was also excluded.

Clinico-pathological data of patients were prospectively collected and computerized. Surgical stage and tumor grade were assigned according to the International Federation of Gynecology and Obstetrics
(FIGO) 1988 criteria. None of the patients received preoperative radiation or chemotherapy. All patients underwent exploratory laparatomy, total hysterectomy and bilateral salpingo-oophorectomy. Lymphadenectomy was performed at the discretion of the surgeon. Radiation therapy after surgery was administered to most of stage II and III patients and to stage I patients with risk factors as deep myometrial invasion and high histological grade. The treatment consisted of irradiation of either the vaginal cuff (45-60 Gy), the whole pelvis (50 Gy), or both. A few patients received irradiation in the whole pelvis and in the para-aortic nodes (45 Gy). Only 4 patients received adjuvant chemotherapy in addition to radiotherapy. Forty non-cancerous endometrial samples were used as control tissue in methylation analysis. The study was approved by the institutional ethical committee and all subjects provided informed consent.

\section{Tissue fractionation, DNA isolation and molecular analyses}

Frozen tumor specimens were macroscopically dissected to enrich for neoplastic cellularity. The tissue was mechanically disrupted and the sub-cellular fractions (cytosolic and nuclear) were obtained as previously described [50]. DNA was extracted by a standard procedure. DNA was also obtained from matching peripheral blood leukocytes and from non-tumoral endometrial tissues.

For MSI classification, five quasi monomorphic mononucleotide markers BAT25, BAT26, NR21, NR24 and NR27 were used according to published conditions and criteria [51, 45]. Tumors were considered MSI when they showed alterations in at least 2 out of five markers. Ninety seven percent of MSI tumors (all but one) were correctly classified by using only BAT-26 and BAT25 . Tumors with only one altered marker $(n=12)$ were classified as MSS [52].

Promoter methylation analysis of $h M L H 1$ gene was performed by methylation-specific PCR (MSP) [53], using previously reported primers and conditions [42, 54]. Methylation of the analyzed $M L H 1$ promoter region invariably correlates with absence of gene expression [55].

Ploidy status and S-phase fraction were estimated by flow cytometry as previously reported [50]. Tumors with a DNA index $>0.9$ and $<1.1$ were classified as "(quasi) diploid" and others as aneuploid.

Single strand conformation polymorphism (SSCP) and DNA sequencing analyses were applied to search for mutations in K-ras (exons 1 and 2), PTEN (exons 1 to 9 and intronic splice sites) and $\beta$-catenin (CTNNB1) (exon 3 mutations and intragenic deletions). Analyses of PTEN and $\beta$-catenin were as described elsewhere [41, 40]. Primer sequences and conditions for $K$-ras mutation analysis are available upon request. Promoter methylation 
analysis of $A P C$ was performed by methylation-specific PCR (MSP) [53], using previously reported primers and conditions [42, 54]. Quantification of estrogen (ER) and progesterone $(\mathrm{PR})$ receptors was done using the labeled hormone exchange method as described [50].

\section{Follow-up}

All patients were routinely followed at 3-month intervals the first 2 years, 6 months until the fifth year, and every year thereafter. Three patients lost in less than 6 months after surgery were excluded. Disease-free survival (DFS) was defined as the time from surgery to recurrence for patients with a disease-free interval after surgery, and cancer-specific survival (CSS) as the time from surgery to cancer-related death. Patients with persistent disease after surgery $(n=9)$ were excluded from DFS analysis. Patients that died by causes other than disease $(n=10)$ were censored at the date of death. The median follow-up was 112 months (range 6-227 months) for all patients and 132 months (range 16-227 months) for patients that did not die by disease.

\section{Statistical analyses}

The relationship among categories established by MSI and ploidy status and categorical variables was analyzed by Chi-square test. ANOVA was used for variables with a Gaussian distribution, and KruskalWallis test for variables with a non-normal distribution. Binary logistic regression analysis was employed to test the independent contribution of demographic variables to MSI development. Survival curves were prepared according to Kaplan-Meier method and compared by the log-rank test. Univariate and multivariate survival analysis was carried out using the Cox proportional hazard model. Demographic and surgicopathological (including treatment) variables were entered to discern their independent contribution to the basic regression model for the multivariate survival analyses. A forward stepwise method was used to test the influence of explanatory variables (with a p-value $<0.1$ in the univariate analysis) in the multivariate regression studies. The analysis of independence was performed by likelihood ratio tests. All analyses were two sided, and statistical significance was set at a p-value $<0.05$. Analyses were carried out using the PASW (version 18.0) statistical package (SPSS, Chicago, IL).

\section{ACKNOWLEDGMENTS:}

Grant sponsors: ICIC, Fundación Canaria de Investigación y Salud (FUNCIS), Agencia Canaria de Investigación, Innovación y Sociedad de la Información del Gobierno de Canarias (CB, JCD-C), and Fondo
Investigaciones Sanitarias of the Instituto de Salud Carlos III (grant FIS PS09/02444).

\section{Editorial note}

This paper has been accepted based in part on peerreview conducted by another journal and the authors' response and revisions as well as expedited peer-review in Oncotarget

\section{DISCLOSURE OF POTENTIAL CONFLICTS OF INTEREST:}

The authors declare no conflicts of interest.

\section{REFERENCES}

1. Siegel R, Ward E, Brawley O, Jemal A. Cancer statistics, 2011: the impact of eliminating socioeconomic and racial disparities on premature cancer deaths. CA: a cancer journal for clinicians. 2011; 61(4):212-236.

2. Lax SF. Molecular genetic pathways in various types of endometrial carcinoma: from a phenotypical to a molecularbased classification. Virchows Archiv : an international journal of pathology. 2004; 444(3):213-223.

3. Prat J, Gallardo A, Cuatrecasas M, Catasus L. Endometrial carcinoma: pathology and genetics. Pathology. 2007; 39(1):72-87.

4. Susini T, Amunni G, Molino C, Carriero C, Rapi S, Branconi F, Marchionni M, Taddei G, Scarselli G. Tenyear results of a prospective study on the prognostic role of ploidy in endometrial carcinoma: dNA aneuploidy identifies high-risk cases among the so-called 'low-risk' patients with well and moderately differentiated tumors. Cancer. 2007; 109(5):882-890.

5. Aaltonen LA, Peltomaki P, Leach FS, Sistonen P, Pylkkanen L, Mecklin JP, Jarvinen H, Powell SM, Jen J, Hamilton SR, et al. Clues to the pathogenesis of familial colorectal cancer. Science. 1993; 260(5109):812-816.

6. Ionov Y, Peinado MA, Malkhosyan S, Shibata D, Perucho M. Ubiquitous somatic mutations in simple repeated sequences reveal a new mechanism for colonic carcinogenesis. Nature. 1993; 363(6429):558-561.

7. Risinger JI, Berchuck A, Kohler MF, Watson P, Lynch HT, Boyd J. Genetic instability of microsatellites in endometrial carcinoma. Cancer research. 1993; 53(21):5100-5103.

8. Duval A, Collura A, Berthenet K, Lagrange A, Garrido C. Microsatellite instability in colorectal cancer: time to stop hiding! Oncotarget. 2011; 2(11):826-827.

9. Perucho M. Cancer of the microsatellite mutator phenotype. Biological chemistry. 1996; 377(11):675-684.

10. Popat S, Hubner R, Houlston RS. Systematic review of microsatellite instability and colorectal cancer prognosis. 
Journal of clinical oncology : official journal of the American Society of Clinical Oncology. 2005; 23(3):609618.

11. Rigas B, Borgo S, Elhosseiny A, Balatsos V, Manika Z, Shinya H, Kurihara N, Go M, Lipkin M. Decreased expression of DNA-dependent protein kinase, a DNA repair protein, during human colon carcinogenesis. Cancer research. 2001; 61(23):8381-8384.

12. Komuro Y, Watanabe T, Hosoi Y, Matsumoto Y, Nakagawa K, Tsuno N, Kazama S, Kitayama J, Suzuki N, Nagawa $\mathrm{H}$. The expression pattern of $\mathrm{Ku}$ correlates with tumor radiosensitivity and disease free survival in patients with rectal carcinoma. Cancer. 2002; 95(6):1199-1205.

13. Grabsch H, Dattani M, Barker L, Maughan N, Maude K, Hansen O, Gabbert HE, Quirke P, Mueller W. Expression of DNA double-strand break repair proteins ATM and BRCA1 predicts survival in colorectal cancer. Clinical cancer research : an official journal of the American Association for Cancer Research. 2006; 12(5):1494-1500.

14. Beggs AD, Domingo E, McGregor M, Presz M, Johnstone E, Midgley R, Kerr D, Oukrif D, Novelli M, Abulafi M, Hodgson SV, Fadhil W, et al. Loss of expression of the double strand break repair protein ATM is associated with worse prognosis in colorectal cancer and loss of $\mathrm{Ku} 70$ expression is associated with CIN. Oncotarget. 2012; 3(11):1348-1355.

15. Hawkins NJ, Tomlinson I, Meagher A, Ward RL. Microsatellite-stable diploid carcinoma: a biologically distinct and aggressive subset of sporadic colorectal cancer. British journal of cancer. 2001; 84(2):232-236.

16. Chang SC, Lin JK, Yang SH, Wang HS, Li AF, Chi CW. Relationship between genetic alterations and prognosis in sporadic colorectal cancer. International journal of cancer Journal international du cancer. 2006; 118(7):1721-1727.

17. Sinicrope FA, Rego RL, Halling KC, Foster N, Sargent DJ, La Plant B, French AJ, Laurie JA, Goldberg RM, Thibodeau SN, Witzig TE. Prognostic impact of microsatellite instability and DNA ploidy in human colon carcinoma patients. Gastroenterology. 2006; 131(3):729-737.

18. Duval A, Reperant M, Compoint A, Seruca R, Ranzani GN, Iacopetta B, Hamelin R. Target gene mutation profile differs between gastrointestinal and endometrial tumors with mismatch repair deficiency. Cancer research. 2002; 62(6):1609-1612.

19. Woerner SM, Benner A, Sutter C, Schiller M, Yuan YP, Keller G, Bork P, Doeberitz M, Gebert JF. Pathogenesis of DNA repair-deficient cancers: a statistical meta-analysis of putative Real Common Target genes. Oncogene. 2003; 22(15):2226-2235.

20. Bilbao C, Ramirez R, Rodriguez G, Falcon O, Leon L, Diaz-Chico N, Perucho M, Diaz-Chico JC. Double strand break repair components are frequent targets of microsatellite instability in endometrial cancer. European journal of cancer. 2010; 46(15):2821-2827.
21. Basil JB, Goodfellow PJ, Rader JS, Mutch DG, Herzog TJ. Clinical significance of microsatellite instability in endometrial carcinoma. Cancer. 2000; 89(8):1758-1764.

22. MacDonald ND, Salvesen HB, Ryan A, Iversen OE, Akslen LA, Jacobs IJ. Frequency and prognostic impact of microsatellite instability in a large population-based study of endometrial carcinomas. Cancer research. 2000; 60(6):1750-1752.

23. Maxwell GL, Risinger JI, Alvarez AA, Barrett JC, Berchuck A. Favorable survival associated with microsatellite instability in endometrioid endometrial cancers. Obstetrics and gynecology. 2001; 97(3):417-422.

24. Black D, Soslow RA, Levine DA, Tornos C, Chen SC, Hummer AJ, Bogomolniy F, Olvera N, Barakat RR, Boyd J. Clinicopathologic significance of defective DNA mismatch repair in endometrial carcinoma. Journal of clinical oncology : official journal of the American Society of Clinical Oncology. 2006; 24(11):1745-1753.

25. Cohn DE, Frankel WL, Resnick KE, Zanagnolo VL, Copeland LJ, Hampel H, Kelbick N, Morrison CD, Fowler JM. Improved survival with an intact DNA mismatch repair system in endometrial cancer. Obstetrics and gynecology. 2006; 108(5):1208-1215.

26. Zighelboim I, Goodfellow PJ, Gao F, Gibb RK, Powell MA, Rader JS, Mutch DG. Microsatellite instability and epigenetic inactivation of MLH1 and outcome of patients with endometrial carcinomas of the endometrioid type. Journal of clinical oncology : official journal of the American Society of Clinical Oncology. 2007; 25(15):20422048.

27. Suehiro Y, Okada T, Okada T, Anno K, Okayama N, Ueno K, Hiura M, Nakamura M, Kondo T, Oga A, Kawauchi $\mathrm{S}$, Hirabayashi K, et al. Aneuploidy predicts outcome in patients with endometrial carcinoma and is related to lack of CDH13 hypermethylation. Clinical cancer research : an official journal of the American Association for Cancer Research. 2008; 14(11):3354-3361.

28. Wik E, Trovik J, Iversen OE, Engelsen IB, Stefansson IM, Vestrheim LC, Haugland HK, Akslen LA, Salvesen HB. Deoxyribonucleic acid ploidy in endometrial carcinoma: a reproducible and valid prognostic marker in a routine diagnostic setting. American journal of obstetrics and gynecology. 2009; 201(6):603 e601-607.

29. Esteller M, Levine R, Baylin SB, Ellenson LH, Herman JG. MLH1 promoter hypermethylation is associated with the microsatellite instability phenotype in sporadic endometrial carcinomas. Oncogene. 1998; 17(18):2413-2417.

30. McCourt CK, Mutch DG, Gibb RK, Rader JS, Goodfellow PJ, Trinkaus K, Powell MA. Body mass index: relationship to clinical, pathologic and features of microsatellite instability in endometrial cancer. Gynecologic oncology. 2007; 104(3):535-539.

31. Malkhosyan SR, Yamamoto H, Piao Z, Perucho M. Late onset and high incidence of colon cancer of the mutator phenotype with hypermethylated hMLH1 gene in women. 
Gastroenterology. 2000; 119(2):598.

32. Slattery ML, Potter JD, Curtin K, Edwards S, Ma KN, Anderson K, Schaffer D, Samowitz WS. Estrogens reduce and withdrawal of estrogens increase risk of microsatellite instability-positive colon cancer. Cancer research. 2001; 61(1):126-130.

33. Yamashita K, Dai T, Dai Y, Yamamoto F, Perucho M. Genetics supersedes epigenetics in colon cancer phenotype. Cancer cell. 2003; 4(2):121-131.

34. Campbell PT, Jacobs ET, Ulrich CM, Figueiredo JC, Poynter JN, McLaughlin JR, Haile RW, Jacobs EJ, Newcomb PA, Potter JD, Le Marchand L, Green RC, et al. Case-control study of overweight, obesity, and colorectal cancer risk, overall and by tumor microsatellite instability status. Journal of the National Cancer Institute. 2010; 102(6):391-400.

35. Notarnicola M, Gristina R, Messa C, Cariola F, Fiorente P, Caruso ML, Gentile M, Di Leo A. Oestrogen receptors and microsatellite instability in colorectal carcinoma patients. Cancer letters. 2001; 168(1):65-70.

36. Walsh MD, Buchanan DD, Cummings MC, Pearson SA, Arnold ST, Clendenning M, Walters R, McKeone DM, Spurdle AB, Hopper JL, Jenkins MA, Phillips $\mathrm{KD}$, et al. Lynch syndrome-associated breast cancers: clinicopathologic characteristics of a case series from the colon cancer family registry. Clinical cancer research : an official journal of the American Association for Cancer Research. 2010; 16(7):2214-2224.

37. Kyushima N, Watanabe J, Hata H, Jobo T, Kameya T, Kuramoto H. Expression of cyclin A in endometrial adenocarcinoma and its correlation with proliferative activity and clinicopathological variables. Journal of cancer research and clinical oncology. 2002; 128(6):307-312.

38. An HJ, Kim KI, Kim JY, Shim JY, Kang H, Kim TH, Kim JK, Jeong JK, Lee SY, Kim SJ. Microsatellite instability in endometrioid type endometrial adenocarcinoma is associated with poor prognostic indicators. The American journal of surgical pathology. 2007; 31(6):846-853.

39. Zysman M, Saka A, Millar A, Knight J, Chapman W, Bapat B. Methylation of adenomatous polyposis coli in endometrial cancer occurs more frequently in tumors with microsatellite instability phenotype. Cancer research. 2002; 62(13):3663-3666.

40. Bilbao C, Rodriguez G, Ramirez R, Falcon O, Leon L, Chirino R, Rivero JF, Falcon O, Jr., Diaz-Chico BN, Diaz-Chico JC, Perucho M. The relationship between microsatellite instability and PTEN gene mutations in endometrial cancer. International journal of cancer Journal international du cancer. 2006; 119(3):563-570.

41. Mirabelli-Primdahl L, Gryfe R, Kim H, Millar A, Luceri C, Dale D, Holowaty E, Bapat B, Gallinger S, Redston M. Beta-catenin mutations are specific for colorectal carcinomas with microsatellite instability but occur in endometrial carcinomas irrespective of mutator pathway. Cancer research. 1999; 59(14):3346-3351.
42. Esteller M, Sparks A, Toyota M, Sanchez-Cespedes M, Capella G, Peinado MA, Gonzalez S, Tarafa G, Sidransky D, Meltzer SJ, Baylin SB, Herman JG. Analysis of adenomatous polyposis coli promoter hypermethylation in human cancer. Cancer research. 2000; 60(16):4366-4371.

43. Kloor M, Michel S, von Knebel Doeberitz M. Immune evasion of microsatellite unstable colorectal cancers. International journal of cancer Journal international du cancer. 2010; 127(5):1001-1010.

44. Risinger JI, Chandramouli GV, Maxwell GL, Litzi T, Berchuck A, Umar A. Gene expression analysis of tumor infiltrating lymphocyte markers in endometrial cancers indicates no significant increases in those cases with microsatellite instability. Cancer biomarkers : section A of Disease markers. 2006; 2(1-2):61-68.

45. Bilbao C, Lara PC, Ramirez R, Henriquez-Hernandez LA, Rodriguez G, Falcon O, Leon L, Perucho M, DiazChico BN, Diaz-Chico JC. Microsatellite instability predicts clinical outcome in radiation-treated endometrioid endometrial cancer. International journal of radiation oncology, biology, physics. 2010; 76(1):9-13.

46. Colombino M, Cossu A, Manca A, Dedola MF, Giordano M, Scintu F, Curci A, Avallone A, Comella G, Amoruso M, Margari A, Bonomo GM, et al. Prevalence and prognostic role of microsatellite instability in patients with rectal carcinoma. Annals of oncology : official journal of the European Society for Medical Oncology / ESMO. 2002; 13(9):1447-1453.

47. Negri FV, Campanini N, Camisa R, Pucci F, Bui S, Ceccon G, Martinelli R, Fumagalli M, Losardo PL, Crafa $\mathrm{P}$, Bordi C, Cascinu S, et al. Biological predictive factors in rectal cancer treated with preoperative radiotherapy or radiochemotherapy. British journal of cancer. 2008; 98(1):143-147.

48. Zauber NP, Marotta SP, Berman E, Grann A, Rao M, Komati N, Ribiero K, Bishop DT. Molecular genetic changes associated with colorectal carcinogenesis are not prognostic for tumor regression following preoperative chemoradiation of rectal carcinoma. International journal of radiation oncology, biology, physics. 2009; 74(2):472476.

49. Wang Q, Ponomareva ON, Lasarev M, Turker MS. High frequency induction of mitotic recombination by ionizing radiation in Mlh1 null mouse cells. Mutation research. 2006; 594(1-2):189-198.

50. Falcon $\mathrm{O}$, Chirino R, Leon L, Lopez-Bonilla A, Torres S, Fernandez L, Garcia-Hernandez JA, Valeron PF, DiazChico JC. Low levels of cathepsin D are associated with a poor prognosis in endometrial cancer. British journal of cancer. 1999; 79(3-4):570-576.

51. Buhard O, Suraweera N, Lectard A, Duval A, Hamelin R. Quasimonomorphic mononucleotide repeats for high-level microsatellite instability analysis. Disease markers. 2004; 20(4-5):251-257.

52. Perucho M. Correspondence re: C.R. Boland et al., A 
National Cancer Institute workshop on microsatellite instability for cancer detection and familial predisposition: development of international criteria for the determination of microsatellite instability in colorectal cancer. Cancer Res., 58: 5248-5257, 1998. Cancer research. 1999; 59(1):249-256.

53. Herman JG, Graff JR, Myohanen S, Nelkin BD, Baylin SB. Methylation-specific PCR: a novel PCR assay for methylation status of $\mathrm{CpG}$ islands. Proceedings of the National Academy of Sciences of the United States of America. 1996; 93(18):9821-9826.

54. Lind GE, Thorstensen L, Lovig T, Meling GI, Hamelin R, Rognum TO, Esteller M, Lothe RA. A CpG island hypermethylation profile of primary colorectal carcinomas and colon cancer cell lines. Molecular cancer. 2004; 3:28.

55. Deng G, Chen A, Hong J, Chae HS, Kim YS. Methylation of $\mathrm{CpG}$ in a small region of the hMLH1 promoter invariably correlates with the absence of gene expression. Cancer research. 1999; 59(9):2029-2033. 